\title{
Constitution and Promotion Strategy on Teachers' Professional Ability for Middle Vocational Undergraduate
}

\author{
Bing Yang \\ College of Finance and Trade, Bohai University, Jinzhou, 121013, China \\ yangbing2884567@163.com
}

Keywords: middle vocational undergraduate; teachers' professional ability; characteristic; constitution; promotion strategy

\begin{abstract}
Improve teachers' professional ability is the necessary way to realize the goal of education and promote teachers' professional development, is the need for a long-term process of teachers' lifelong efforts. In this paper, according to the characteristics of the middle vocational undergraduate teachers' professional ability, proposed middle vocational undergraduate teachers' professional competence, formulate the development strategy and improve the capacity. Specific strategies include: build a complete knowledge system promote the teachers' professional ability and improved, innovative secondary vocational undergraduate teacher professional ability development the new mechanism, constructing the new teacher evaluation system with the characteristic of secondary vocational undergraduate education, training, and improve and special ability to adapt to the reform of vocational education and realize the positive interaction of teaching research and teaching practice. The research results of this article, for teachers, colleges, universities and the competent department of education and improve middle vocational undergraduate teachers' professional ability by established practical and feasible strategies and action plans.
\end{abstract}

\section{Introduction}

Professional ability is a combination of people engaged in a professional capacity. Basic elements including three aspects: one is to do specific professional and must have ability, show the qualification; Secondly, the professional quality of participate in the work performance; Thirdly, career management skills after start a career. Teachers' professional ability is a teacher with excellent teaching and education method is characterized by education tasks of the ability of professional activities, is done teaching teachers engaged in education activities, to achieve the teaching goal, cultivating qualified talents for the society all the necessary professional ability. Teachers' professional ability is in the teachers "education teaching ability, on the basis of accumulating experience through the education practice, constantly improve themselves, continuously innovation and development of a qualified teacher should have the full ability". The development and improvement of teachers' professional ability is in today's society, culture and education reform objective demands on teachers is an important part of teachers' professional development, is the need for a long-term process of teachers' lifelong efforts.

Middle vocational undergraduate students is a special group, most of them has the bad grades in junior high school, so choose to secondary vocational technical school. Theory of most of the students learning enthusiasm is not high, the lack of spirit, lack of active learning motivation, learning and poor basis. But the students' mental quality is not bad, the thought is agile, beginning ability is stronger, for easy to accept new things and new ideas, strong adaptability. Secondary vocational undergraduate students has the characteristics of different from ordinary undergraduate students, therefore, secondary vocational undergraduate teachers also need to have different from ordinary undergraduate teacher professional ability. Based on the teachers' professional development theory, lifelong education theory, career development theory and teaching theory under the guidance of wisdom, combined with the actual investigation and analysis, a clear secondary vocational undergraduate teachers' professional ability improving and developing the 
existing problems, and analysis of professional competence, set and development strategy, improve the capacity for secondary vocational undergraduate teachers to renew the idea of education, to improve the teaching effect and promote teachers' professional development to provide advice, and then to improve the quality of teaching of undergraduate course of secondary vocational service.

\section{Characteristic on Teachers' Professional Ability for Middle Vocational Undergraduate}

The difference of different profession, make each profession's role and assume the responsibility of the show different characteristics, inherent to the particularity of each profession. Secondary vocational undergraduate teacher professional ability both has the general features of ordinary teachers' professional ability, but also has particularity. Summarized as follows:

(1) Situationality [1]. Teaching activity as a kind of complex activities, with the characteristics of the various elements cross interaction. Can secondary vocational undergraduate teachers' professional ability is embodied in general knowledge and skills of teaching and teaching situation, the combination of teaching conditions, teaching according to different objects and complicated problems to make appropriate decisions and rulings, which take different suitable for situation of behavior and ways.

(2) Variability. Teaching is a complicated process, need in accordance with the law of development and features of the students use different ways of training. Teachers should according to different teaching situation, the teaching object and teaching task is complicated phenomenon, according to their aptitude, to achieve the target, according to different situation, different behavior and ways to make the corresponding judgment or processing.

(3) Innovation. Innovation education is the core content of quality education. Teachers' innovation ability directly affects the students' innovation ability. Teachers' innovative thinking ability affects the creative thinking ability of students, teachers' creative spirit, will promote the improvement of students' innovative ability. Only those teachers with innovation spirits and innovation consciousness and the modern education concepts, can cultivate students' innovation ability.

(4) Development. Education is a continuous learning process in one's lifetime. Lifelong learning will become an inevitable trend. To train talents for the country's teachers, more should with lifelong education as the goal, to the lifelong learning throughout his life, constantly improve their professional knowledge and professional ability, constantly absorbing the field and related fields of knowledge, constantly improve and develop themselves.

\section{Constitution on Teachers' Professional Ability for Middle Vocational Undergraduate}

Study of constitution on Teachers' Professional Ability for Middle Vocational Undergraduate is a complicated system engineering, domestic and foreign experts and scholars to the teachers' professional ability was systematically studied, mainly concentrated in the education, scientific research, teaching and self-development, etc. Refer to previous research results, combined with the actual situation of secondary vocational undergraduate education, this article sum up teacher's professional ability structure as shown in Fig.1.

(1) Teaching organization ability. In classroom teaching, the teacher through management class order and focus students' attention, arouse students' learning interest, arouse the enthusiasm of students learning, and to create the teaching situation of appropriate, improve teaching efficiency and achieve the teaching goal of a kind of behavior.

(2) Hold the textbook ability. The teaching material is the main medium of information in knowledge activities, is the carrier of way of teaching contents teaching, is the important tool to realize training target. In the process of teaching how to use the teaching material, grasping the core content of good teaching material is the key.

(3) Control classroom ability, classroom Control ability is the key to the success of classroom teaching. To let the students actively participate in teaching activities, in the situation to introduce, 
stimulate students' interest, improve the efficiency of classroom teaching; In the process of exploring, guide students to active participation, improve the efficiency of classroom teaching.

\begin{tabular}{|c|c|}
\hline \multicolumn{1}{|c|}{ Teachers' professional ability for middle vocational undergraduate } \\
\hline Teaching organization ability & Psychological counseling ability \\
\hline Hold the textbook ability & Information technology ability \\
\hline Control classroom ability & Social practice ability \\
\hline Language expression ability & Vocational guidance ability \\
\hline Edofessional technology ability & Vocational development ability \\
\hline
\end{tabular}

Fig. 1. Constitution on teachers' professional ability for middle vocational undergraduate

(4) Language expression ability. Language is a teacher to the students, to express knowledge, spread of civilization, enlighten students' intelligence, shaping students' mind the basic tool and a bridge. Teachers' language expression ability strong and the weak direct relation to the success or failure of education and teaching, teachers must pay attention to the improvement of language competence.

(5) Professional technology ability, Professional technology is specialized in a particular work or job to need the leadership of the working knowledge, theoretical knowledge and skills, etc. Teachers of different subjects have different professional and technical ability.

(6) Education and research ability. Education research is applied to the actual operation ability to solve the problem of corresponding education scientific research situation, mainly including find problem ability, design capabilities, information filtering capacity, implementation, operation ability and written expression ability.

(7) Psychological likely ability. The Psychological counseling is changing individual self-awareness by verbal communication skills, so as to improve its capacity of Psychological support and guidance method. The development of modern education, requires teachers are not only the human culture transmission, also should be the student psychology shaper, is the supporter of students' mental health.

(8) Information technology ability. In the era of education informationized, the overall quality of teachers must be able to adapt to the modern education, is widely used in the teaching of multimedia technology to improve education quality of teaching, promote students' Information quality enhances unceasingly, to promote Information technology, and ultimately achieve the goal of cultivating innovative talents.

(9) Interpersonal communication ability [2]. In education teaching work, teachers have to deal with all kinds of relationships. Include its relationship with students, and the relationship between colleagues and leaders, and the relationship between the parents, as well as the relationship between other industries of society. These relationships are handled appropriately, affects teachers' education and teaching effect.

(10) Social practice ability. Practical ability is the main body using the relevant theories, knowledge, experience and tools, have a purpose, the ability to consciously know or transform the object. Secondary vocational undergraduate teachers through the social practice, to master the latest dynamic social demand, improve the ability to analyze and solve problems.

(11) Vocational guidance ability. Vocational guidance is an important part of higher talents cultivation, promote students' employment, planning career development and enhance the vitality of school. Vocational guidance is one of the secondary vocational undergraduate teachers' job content, using the multi-disciplinary knowledge to students for professional training and personalized vocational guidance. 
(12) Vocational development ability. The teacher development is the process of teachers' life value realization, is a teacher on the basis of fully understanding the meaning of education, enhance the spirit of pursuit, enhance the professional ethics, master the law of education, expand the subject knowledge, strengthen their professional skills and improve the level of education the teaching process.

\section{Promotion Strategy on Teachers' Professional Ability for Middle Vocational Undergraduate}

Strategy is a scheme collection to achieve target. According to the characteristic of middle vocational undergraduate teachers' professional ability and structure, combined with the author's own teaching management and scientific research experience, with reference to the research results of others [3], to develop secondary vocational undergraduate professional ability of teachers to promote strategy is as follows:

(1) Build a complete knowledge system to promote the teachers' professional ability and improved. Teachers' knowledge system is the important condition of teachers' education teaching work, is gradually formed in the study and practice of knowledge set. Perfect knowledge system to help teachers improve work efficiency, enhance the core competition of the individual, to improve the teaching quality, promote teachers' professional development. The composition of knowledge system including knowledge, curriculum knowledge, teaching knowledge, students' characteristics, environmental context knowledge education, teaching methods and teaching strategies, etc.

(2) Middle vocational undergraduate teacher professional ability development mechanism innovation. Mechanism is based on certain parts of works to take things, to coordinate them to run and play a role. Standardize the management system of teachers' professional ability development, open development channels, and make the teachers' ability to promote legalization and institutionalization; establish talent incentive mechanism, fully arouse the enthusiasm of teachers, and expand the teachers' ability to improve space, encourage the development of teachers' professional ability, outstanding secondary vocational undergraduate teachers' skills and practice.

(3) Build the new teacher evaluation system with the characteristic of middle vocational undergraduate education. Teacher evaluation is the teaching thoughts, teaching behavior, teaching effect and the professional level in the process of value judgment. Build a challenging and encouraging new evaluation system and it can promote students' development and improve the teachers' professional ability. On the basis of competence-based education idea, form the school students, colleagues, and their own multivariate evaluation main body, promote teachers constantly enrich theory knowledge, practice skills, enhance the level of scientific research and play an important role in the evaluation to promote teachers' growth.

(4) Training and improving special ability and adapt to the reform of vocational education. Middle vocational undergraduate is the advanced form of professional technical schools, teachers should constantly improve their professional abilities, to adapt to the rapid development and change of social environment and professional environment. Including improving and adapt to the reform of vocational education teaching ability, pay attention to the career guidance teachers abilities, improve teachers' participation in social practice ability and cultivate teachers' education management ability, strengthen the public relation ability of the teachers, etc.

(5) Achieve positive interaction teaching research and teaching practice. Combining the teaching and scientific research, in order to promote scientific research, teaching with scientific research to promote teaching, construction of teaching and research integration model, realize the benign interactive development for teaching and scientific research. Teaching research was applied to teaching practice, with the problems found in teaching practice to promote teaching and research, effect on each other and promote each other, improve teachers' teaching and scientific research ability.

\section{Conclusion}

Improve the level of teachers' professional ability, and promote the teacher professional 
development is the common goal of education around the world, is the important guarantee of realizing strategy relying on science and education in our country, is also the only way for the general teachers grow up. New curriculum reform process, increasingly, to the teachers put forward higher request. On the one hand, the teacher must learn the forefront of education teaching theory, improve their comprehensive quality, and constantly grasp the opportunity, advancing with The Times, actively participate in their own development, new teachers to be good; On the other hand, the education administrative departments and schools for the development and improvement of teachers' professional ability to provide more and better platform. Secondary vocational undergraduate course teachers should according to their own characteristics and the characteristics of students, combining with the results of this paper to develop professional ability promotion planning. This article research results, for teachers, colleges and universities, and improve secondary vocational undergraduate teachers' professional ability by the competent department of education established practical and feasible strategies and action plans, to promote the development of secondary vocational undergraduate education has a certain role in promoting.

\section{References}

[1] X. T. Yang, "Higher capacity of the institutions of the teaching profession: Base On Guangzhou City Vocational College," Master's degree of Jinan University, 2008.

[2] Y. Tian, "On the construction of College Teachers' teaching ability and its cultivation mechanism," China Adult Education, vol. 16, no. 24, pp. 102-104, 2012.

[3] C. Y. Xu, "Research on the strategy of improving the ability of "Double Teachers" teachers in Higher Vocational Colleges," Journal of Changchun Education Institute, vol. 31, no. 19, pp. 104-105, 2015.

[4] C. W. Li, "Research on the promotion and development strategy of teachers' professional ability," Master's degree of Henan Normal University, 2014.

[5] H. Z. Ru, "Exploration on the management of teachers' individual knowledge system," The Inservice Education and Training of School Teachers, vol. 29, no. 1, pp. 14-17, 2012.

[6] L. W. Lu, "Research on the path of Higher Vocational Teachers' professional ability promotion," Education for Chinese After-school, Web publishing address: http://www.cnki.net/KCMS/detail/11.3173.G4.20140915.0852.089.html, 2014-09-15.

[7] C. Yu, "Strategies to improve the teaching ability of young teachers in Colleges and Universities," Journal of Shenyang Normal University (Social Science Edition), vol. 38, no. 1, pp. 124-126, 2014. 